\title{
Large and small fibre type sensory dysfunction in patients with cancer
}

\author{
R B Lipton, B S Galer, J P Dutcher, R K Portenoy, V Pahmer, F Meller, J C Arezzo, \\ P H Wiernik
}

\begin{abstract}
Quantitative sensory testing was used to assess the prevalence of sensory dysfunction in patients with cancer, carefully screened for other risk factors for neuropathy. Large fibre type sensory function was evaluated using vibration threshold (VT) determinations while small fibre type sensory function was assessed by thermal threshold (TT) determinations. Mean VT and TT were significantly elevated in the toes but not the fingers of cancer patients. VT elevations in the toes occurred in $31 \%$ of cancer patients and in $6 \%$ of control subjects. TT elevations in the toes occurred in $43 \%$ of cancer patients and $4 \%$ of control subjects. Based on these findings it is concluded that large and small fibre type sensory dysfunction is much more common in carefully screened cancer patients than in control subjects. This sensory dysfunction is most likely to represent a neuropathy related directly or indirectly associated with cancer.
\end{abstract}

Peripheral neuropathy commonly occurs in patients with systemic malignancy. Nerve damage may result from direct effects of the malignancy, including extrinsic compression or infiltration, associated metabolic disturbances, chemotherapy or poorly understood remote effects. ${ }^{1-5}$ Neuropathies have been associated with carcinoma of the lung, especially oat cell carcinoma, ${ }^{12910}$ lymphoma, multiple myeloma and a number of other malignancies. ${ }^{357}$ Though most surveys have relied on clinical criteria to identify patients with neuropathy 4910 several reports have utilised standard electrophysiological procedures. $^{36-8}$

In an earlier report, we used quantitative sensory testing (QST) to screen a cancer population for large fibre type sensory dysfunction. ${ }^{22}$ Specifically, we measured vibration threshold (VT), which reflects function in large diameter, heavily myelinated peripheral nerves and the dorsal column medial lemniscal system with which they interact. ${ }^{17-19}$ We found significant VT elevations in $12 \%$ of cancer patients and only $1.7 \%$ of control subjects. VT elevations were statistically related to the presence of a neoplasm rather than to identifiable risk factors for neuropathy. Although this study demonstrated the potential utility of QST in assessing sensory function in cancer patients it was limited by several important factors. First, a number of patients with diabetes, alcoholism, or a history of treatment with neurotoxic chemotherapeutic agents were included. Second, VTs were determined only in the upper extremity. Studies of the lower extremity might dramatically increase the yield, since axonopathies affect peripheral nerves in proportion to their length. Third, the study assessed large fibre type function using VT but did not evaluate small fibre type function. Small fibre dysfunction can now be assessed using a psychophysical method to determine the thermal threshold (TT). This measure reflects the functional status of small nerve fibres and the spino-thalamic pathways with which they interact. ${ }^{192}$ To address these issues we have determined both VT and TT in the hands and feet of cancer patients free of identifiable risk factors for neuropathy.

\section{Patients and methods \\ Subjects}

Quantitative sensory testing was performed in 29 selected patients with cancer treated at the affiliated hospitals of the Albert Einstein College of Medicine, New York. Patients with identifiable risk factors for neuropathy, other than malignancy itself, were excluded. Exclusion criteria included history of diabetes or current chemical diabetes (spot blood sugar greater than $150 \mathrm{mg} / \mathrm{dl}$ ), history of alcohol abuse (history of more than three drinks per day for at least one month), renal disease (creatinine greater than 1.8), cachexia, thyroid disease, B12 deficiency, and folate deficiency. Patients treated with neurotoxic chemotherapeutic agents (vinca alkaloids, cisplatinum, taxol, adriamycin) were also excluded, as were patients receiving other neurotoxic medications (that is, hydralazine, nitrofurantoin, disulfiram, chloramphenicol and phenytoin). Age, gender, type of malignancy, clinical status, sensory symptoms and the results of a neurological examination were all recorded.

A control population consisting of 100 healthy subjects, who ranged in age from 2776 years and were free of alcoholism, diabetes and history of neurological disease was tested using the same procedures.

\section{Quantitative sensory testing}

VT and TT were assessed in the nondominant index finger and the big toe. VT was assessed using the Vibratron I, a device consisting of two rods which protrude through a perspex plate which can be contacted either 
with the fingers or toes. The subject rests the index finger or big toe on each rod in sequence, for one second. The amplitude of vibration delivered varies as a function of voltage. On each trial only one rod vibrates, always at a fixed frequency of $120 \mathrm{~Hz}$. The subject is asked to choose the vibrating rod on each trial, using a two-alternative forcedchoice procedure. Testing begins at an intensity of vibration detectable on $100 \%$ of trials. The intensity of vibration is decreased until subjects correctly identify the vibrating rod $50 \%$ of the time, the level predicted by chance alone. VT was determined by selecting the five lowest correct choices and the five highest incorrect choices, eliminating the highest and lowest scores and averaging the remaining scores. This procedure is discussed in more detail elsewhere. ${ }^{17-20}$

TT was evaluated in the first 14 of the 29 subjects tested, using the Sensortek Thermal Tester, described more fully elsewhere. ${ }^{21}$ The remaining 15 patients were not tested because the device was not available. The Thermal Tester controls the temperature of two molybdenum plates and provides a digital readout of temperature. The reference plate is kept at room temperature $\left(25^{\circ} \mathrm{C}\right)$ while the temperature of the other plate is varied. TT was determined using a two-alternative forced-choice paradigm similar to the one described above for VT determination. For the initial trial, the temperature difference between the two plates is set at a level detectable $100 \%$ of the time. After touching each plate for one second, the subject is asked to choose the cooler of the two plates. The temperature difference between the plates is then reduced in $10 \%$ decrements as described for VT determinations above. TT was calculated in a manner identical to VTs, as described above.

\section{Results}

The mean ages of patients with cancer $(56.8$ years) and of control subjects ( 52.3 years) were not significantly different. Types of malignancy represented in the cancer group included breast (12), colon (4), myeloma (3), lymphoma (3), leukaemia (2), gastric (2), prostate (2), and ovarian (1). No relationship was detected between type of malignancy and elevation of sensory thresholds.

Mean VT were significantly elevated in the toes, but not the fingers, of cancer patients (table 1). These results were confirmed by a multiple linear regression model which treated each group as a dichotomous variable (control $=0$, cancer $=1$ ) and age as a continuous variable. In this model, age but not group was significantly associated with VT in the finger; age and group were significantly associated with VT in the toe (table 2). Large fibre type sensory dysfunction, defined by a VT which exceeds the control group mean by at least two standard deviations, occurred in the fingers of $6.9 \%$ and in the toes of $31 \%$ of cancer patients. In the toes, the proportion of cancer patients with large fibre type sensory dysfunction was significantly greater than the corresponding proportion for control subjects (table 3).

Mean TT were also significantly elevated in the toes, but not the fingers of cancer patients (table 1). Multiple linear regression confirmed these results. Age, but not group was significantly associated with TT in the finger. Age and group were significantly associated with TT in the toe (table 2). Small fibre type sensory dysfunction, defined by a TT which exceeds the control group mean by at least two standard deviations, occurred in the fingers of $7 \cdot 1 \%$ and in the toes of $42.9 \%$ of cancer patients. Table 3 shows that the proportion of subjects with small fibre type sensory dysfunction was significantly greater in cancer patients than in

Table 1 Mean vibration thresholds (VT) and thermal thresholds (TT)

\begin{tabular}{|c|c|c|c|c|}
\hline & $\begin{array}{l}\text { Patients with cancer } \\
\text { Mean /(SD) } \\
n=\text { Sample size }\end{array}$ & $\begin{array}{l}\text { Controls } \\
\text { Mean/(SD) } \\
n=\text { Sample size }\end{array}$ & t-value & $P$ \\
\hline $\begin{array}{l}\text { Mean vi } \\
\text { Finger } \\
\text { Toe }\end{array}$ & $\begin{array}{l}\text { eshold }(V U)^{1} \\
3 \cdot 57 /(1 \cdot 84) \mathrm{n}=29 \\
8 \cdot 17 /(7 \cdot 54) \mathrm{n}=29\end{array}$ & $\begin{array}{l}3 \cdot 26 /(1 \cdot 02) \mathrm{n}=100 \\
5 \cdot 97 /(2 \cdot 00) \mathrm{n}=100\end{array}$ & $\begin{array}{l}1 \cdot 18 \\
2 \cdot 63\end{array}$ & $\begin{array}{l}\text { NS } \\
0.010\end{array}$ \\
\hline $\begin{array}{l}\text { Mean th } \\
\text { Finger } \\
\text { Toe }\end{array}$ & $\begin{array}{l}\text { shold }\left({ }^{\circ} \mathrm{C}\right) \\
0.72 /(0 \cdot 40) \mathrm{n}=14 \\
3.67^{2} /(5 \cdot 01) \mathrm{n}=14\end{array}$ & $\begin{array}{l}0.77 /(0.33) n=100 \\
1 \cdot 13 /(0.63) n=100\end{array}$ & $\begin{array}{l}0.57 \\
4.94\end{array}$ & $\begin{array}{l}\text { NS } \\
<0.001\end{array}$ \\
\hline
\end{tabular}

Table 2 Effects of group and age on vibration threshold and thermal threshold in the big toe-multiple linear regression

\begin{tabular}{lllc}
\hline & $a)$ Thermal threshold-toe & & p-value \\
Variable & $b$ & $S E$ & $<0.0001$ \\
Group* & 2.510 & 0.500 & 0.0056 \\
Age & 0.038 & 0.014 & - \\
Constant & -0.877 & 0.730 & $p$-value \\
& b) Vibration threshold-toe & & 0.043 \\
Variable & $b$ & $S E$ & $<0.0001$ \\
Group & 1.550 & 0.760 & -
\end{tabular}

* Multiple regression models using group as a dichotomous variable (control $=0$, cancer $=1$ ) and age as a continuous variable were developed for QST scores for each modality (VT and TT) at each location. Group was not associated with VT or TT in the finger; these models are therefore not shown. 
Table 3 Sensory dysfunction in patients with cancer and in control subjects

\begin{tabular}{|c|c|c|c|c|c|c|}
\hline \multirow[b]{3}{*}{$\begin{array}{l}\text { Vibration thresholds } \\
\text { Finger } \\
\text { Toe }\end{array}$} & \multicolumn{6}{|c|}{ Subjects with sensory dysfunction ${ }^{\star}$} \\
\hline & \multicolumn{2}{|c|}{ Patients with cancer } & \multicolumn{3}{|l|}{ Controls } & \multirow[b]{2}{*}{$\begin{array}{l}\text { NS } \\
0.01\end{array}$} \\
\hline & $\begin{array}{l}\text { Number } \\
2 / 29 \\
9 / 29\end{array}$ & $\begin{array}{l}\% \\
6.9 \\
31.0\end{array}$ & $\begin{array}{l}\text { Number } \\
4 / 100 \\
6 / 100\end{array}$ & $\begin{array}{l}\% \\
4 \\
6\end{array}$ & $\begin{array}{l}x^{2} \\
0.015 \\
6.58\end{array}$ & \\
\hline $\begin{array}{l}\text { Thermal thresholds } \\
\text { Finger } \\
\text { Toe }\end{array}$ & $\begin{array}{l}1 / 14 \\
6 / 14\end{array}$ & $\begin{array}{r}7 \cdot 1 \\
42 \cdot 9\end{array}$ & $\begin{array}{l}3 / 100 \\
4 / 100\end{array}$ & $\begin{array}{l}3 \\
4\end{array}$ & $\begin{array}{r}6.57 \\
11 \cdot 40\end{array}$ & $\begin{array}{l}0.01 \\
0.0007\end{array}$ \\
\hline
\end{tabular}

* Sensory dysfunction is defined by a VT or TT which exceeds the control group mean by greater than 2 standard deviations (see text).

control subjects for the toes but not for the fingers.

Of the 14 cancer patients with both VT and TT assessed, only two had elevated thresholds in both modalities. Both of these subjects had significant VT elevations in the toe, while TT was significantly elevated in the toe in one and in the finger in the other. In five of these 14 subjects $(35 \cdot 7 \%)$ the only significant abnormality was TT in the toe. Seven of these subjects $(50.0 \%)$ had no abnormality in either modality.

\section{Discussion}

These data demonstrate that in cancer patients without other risk factors for neuropathy, VT and TT in the toe are elevated in comparison with age matched controls. Sensory dysfunction was identified by QST in a remarkably high proportion of cancer patients. There was evidence for large fibre type sensory dysfunction in the fingers and/or toes in $37.9 \%$ of cancer patients, while evidence for small fibre dysfunction occurred in $50.0 \%$. In previous reports, the prevalence of clinical neuropathy in cancer patients has ranged from $1 \cdot 7$ to $5 \cdot 5 \%$. $^{3}$ Electrophysiological evidence of neuropathy has been reported in 17 to $31 \%$ of cancer patients, ${ }^{78}$ while histological evidence of nerve damage has been described in up to $44 \%$ of unselected patients with malignancy. ${ }^{6}$

VT elevation is most likely to be the psychophysical correlate of the previously described structural and electrophysiological abnormalities of peripheral nerve, associated with cancer. $^{6-8}$ In our previous report, $12 \%$ of patients had a large fibre type sensory dysfunction, defined by VT in the finger which exceeded the mean of age-matched controls by two SD. ${ }^{22}$ In this study, $6.9 \%$ of subjects had finger VT elevations which exceeded this standard. Large fibre type sensory dysfunction was much more common in the toes than in the fingers; examination of the lower extremity probably yields a more accurate estimate of the prevalence of this abnormality, as expected if it reflects a length dependent axonopathy.

Subclinical small fibre type function has not been previously assessed in cancer patients. TT is most likely the psychophysical correlate of small fibre function, predominantly of the A-delta small myelinated type. ${ }^{23}$ In this study, seven of $14(50 \%)$ cancer patients had a small fibre type dysfunction, occurring in the toe in six of the seven patients. The striking proportion of patients with TT elevations suggests that small fibre neuropathy may be commonly associated with cancer. The majority of patients with small fibre type sensory dysfunction did not have large fibre dysfunction, suggesting that these phenomena may be independent. However, both patients with large fibre dysfunction, that also had small fibre function measured, exhibited small fibre abnormalities, whereas the converse was not true; five of fourteen patients $(35 \cdot 7 \%$ ) had abnormal small fibre function in the toe with normal large fibre function. Standard electrophysiological procedures assess only large, not small fibre function, and therefore cannot be used to confirm these results.

The results cannot be attributed to nonspecific phenomena, such as lack of motivation, inattention or medication effects because subjects with vibration threshold abnormalities in the feet often had normal vibration thresholds in the hands and normal thermal thresholds. These nonspecific phenomena would be expected to impair thresholds on all tests performed.

These findings must be interpreted cautiously. Replication in a larger sample is needed. Moreover, QST does not differentiate functional derangements at various levels of the afferent pathway. Though it has been widely used to screen for neuropathy, abnormalities in some patients may reflect disease of the central somatosensory pathways. Finally, patients with elevated sensory thresholds did not receive additional evaluation. It would be helpful to evaluate these patients with routine nerve conduction studies and to obtain additional nutritional assessments.

Notwithstanding these caveats, this study confirms that VT are elevated in a significant proportion of cancer patients and that the proportion is greater when the lower extremity is studied. TT are also elevated in a significant proportion of patients with cancer, suggesting that small as well as large fibre neuropathy may occur in these patients. Finally, by studying patients carefully screened to eliminate other identifiable causes of neuropathy, these data support the hypothesis that sensory dysfunction may be directly related to an effect of the neoplasm, or an as yet unidentified variable strongly associated with neoplasm. Additional studies using QST in combination with nerve conduction studies, metabolic and nutritional assessment, as well as immunological studies may help to further define the prevalence, pattern and aetiology of neuropathy in patients with cancer. 
We thank Dr Herbert Schaumburg for his support and helpful suggestions and Ms Donna Platyan and Ann Dempsey for expert assistance in the preparation of the manuscript. These findings were presented, in part, at the 1989 meeting of The American Academy of Neurology.

Supported in part by Cancer Center Core Grant CA-13330-17 awarded by $\mathrm{NCl}$, DHHS

1 Grauss F, Cordon-Cardo C, Posner JB. Neuronal antinuclear antibody in sensory neuropathy from lung cancer. Neurology 1985;35:538-43.

2 Horwich MS, Cho L, Parro RS, et al. Subacute sensory neuropathy: A remote effect of carcinoma. Ann Neurol 1977;2:7-19.

3 McLeod JG. Carcinomatous neuropathy. In: Dyck PJ, Thomas PK, Lambert EH, et al. eds. Peripheral Neuropathy. Philadelphia: WB Saunders, 1984:2180-92.

4 Croft $\mathrm{PB}$, Urich $\mathrm{H}$, Wilkinson $M$. Peripheral neuropathy of sensorimotor type associated with malignant disease. Brain 1967;90:31-64.

5 Schaumburg HH, Spencer PS, Thomas PK. Disorders of Peripheral Nerves. Philadelphia: FA Davis, 1983:157-66. 6 Hildebrand J, Coers C. The neuromuscular function in patients with malignant tumors. Brain 1967;90:67.

7 Moody JF. Electrophysiological investigations into the neurological complications of carcinoma. Brain 1965; 88: $1023-41$.

8 Trojaborg $W$, Frantzer E, Andersen I. Peripheral neuropathy and myopathy associated with carcinoma of the lung. Brain 1969;90:71-82.

9 Dyck PJ, Kiely JM. Differential diagnosis of neuropathy associated with cancer. In: Thompson RA, Green JR, eds. Advances in neurology (vol 15). New York: Raven Press, 1976:149-61.

10 Grauss F, Elkin K, Cordon-Cardo C, et al. Sensory neuropathy and small cell lung cancer: Antineuronal neuropathy and small cell lung cancer: Antineuronal 1986;80:45-52.
11 Bradley WG, Lassman LP, Pearce W, et al. The neuropathy of vincristine in man: Clinical, electrophysiological and pathological studies. $J$ Neurol Sci 1970;10:107-31.

12 Casey EB, Jellier AM, LeQuesne PM, et al. Vincristine neuropathy: Clinical and electrophysiological observation. Brain 1973;96:69-86.

13 Green LS, Donoso A, Heller-Bettinger, IH, et al. Axonal transport disturbances in vincristine-induced peripheral neuropathy. Ann Neurol 1977;1:255-62.

14 Lipton RB, Dutcher JP, Berger A, et al. Early detection of Jith Clin Oncol 1985;21:261.

15 Young DE, Posner JB. Nervous system toxicity of chemotherapeutic agents, In: Vinken PJ, Bruyn GW, eds. therapeutic agents, In: Vinken PJ, Bruyn GW, eds. Holland, 1980:91-129.

16 McLeod JG, Penny R. Vincristine neuropathy: An electrophysiological and histological study. J Neurol Neurosurg Psychiatry 1969;32:297-304.

17 Arezzo JC, Schaumburg HH, Petersen CA. Rapid screening for peripheral neuropathy: A field study with Optacon. Neurology 1983;33:626-9.

18 Arezzo JC, Schaumburg $\mathrm{HH}$, Laudadio C. The Vibratron: A simple device for quantitative evaluation of tactile vibration sense. Neurology 1985;35 (Suppl 1):169.

19 Bove MS, Litwak MS, Arezzo JC, Baker E. Quantitative sensory testing in occupational medicine. In: E Baker, ed. Seminars in occupational medicine. New York: Thieme Seminars in occupational medicine.

20 Moody L, Arezzo JC, Otto D. Screening occupational populations for asymptomatic or early peripheral

21 Arezzo JC, Schaumburg HH, Laudadio C. Thermal sensitivity Tester: Device for quantitative assessment of thermal sense in diabetic neuropathy. Diabetes 1986; 35:590-2.

22 Lipton LB, Galer BS, Dutcher JP, et al. Quantitative sensory testing demonstrates that subclinical sensory neuropathy is prevalent in patients with cancer. Arch Neurol 1987;44:944-6.

23 Hensel $H$. Thermoreception and temperature regulation. New York: Academic Press, 1981. 